\title{
Steel ropes in machines opencast mining
}

\author{
Grzegorz Olszyna \\ AGH University of Science and Technology, Poland \\ Vlada Gašić \\ University of Belgrade, Serbia
}

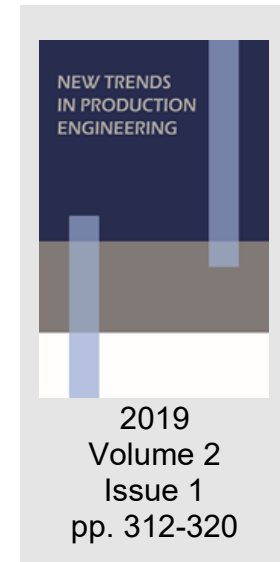

Date of submission to the Editor: 05/2019

Date of acceptance by the Editor: 07/2019

\section{INTRODUCTION}

Multibody excavators in opencast mining are equipped with rope systems for controlling the mining body in the form of a pulley system or systems for maintaining the stability of the structure through rope systems in the form of rope guy (extraction). Steel ropes, both working in pulley systems and lashings, belong to the group of non-renewable technical objects and are commonly used to support these structures. Working time depends on their technical condition and can not be determined unambiguously during routine tests. The technical condition of the ropes determines the wear processes for which, in normal operation, they consist of parametric processes related to material fatigue and mass losses caused by corrosion and clashes. Steel ropes are postponed after achieving an arbitrarily set down criterion (Tytko 2011). Throughout the entire period of use, tests are carried out to determine the current level of wear. These tests are based on non-destructive methods - by magnetic, radiographic or visual methods. The most widespread of these methods are visual test, measurement of parameters and geometrical structural features as well as magnetic tests. Periodic test results are used to make the correct predictive diagnosis, allowing to determine, in a timely manner, the transition to the worklessness of the elements.

Steel ropes operating in multi-bucket excavator systems are subject to wear processes as in many other rope equipment, but their nature of work is crucial, due to the provision of work in the process of producing energy in opencast mining. Pulley systems are the basic assembly that performs the work of lifting or reversing the movement of large masses.

These systems work in many devices, such as construction cranes, crane devices, mobile cranes, cranes, winches for floating cranes, as well as in lifting (deceiving) systems of various single and multi-bucket excavators commonly used in opencast mining (Kasztelewicz 2012, Tytko 2003). The work of ropes in these devices is very difficult and responsible. Both extraction lines in multi- 
bucket excavators and pulley blocks have long pulls and kinematics of work, which affects the work of both ropes and the entire machine. The wear of ropes leads to degradation of elements through degradation processes. Loss of mechanical and structural properties results in weakening and lowering the level of safety. In almost all devices used for the use of wire ropes, a wear process is observed, resulting in loss of the load-bearing section of the rope due to corrosion, material fatigue and clashes (Olszyna, Tytko 2015). In the case of guy ropes, the corrosive agent is the basic component. There is also fatigue consumption, although the extraction ropes are designed to carry mainly longitudinal loads. Spiral construction of guy ropes, different rope tensions resulting from the process of wire production and assembly processes, low values of safety coefficients, longitudinal and transverse oscillation oscillations mean that in some cases the wires of guy ropes work in the area of limited fatigue durability. After some time they break. The above wear factors are revealed as a loss of the rope support cross section and can be identified. In order to ensure an adequate level of safety, tests are necessary to verify their technical condition.

\section{METHOD AND RESEARCH OBJECTS}

As a result of replacing the set of guy ropes in the multi-bucket excavator, samples for strength tests were obtained (Tytko 2006). The tests were carried out mechanical properties of wires. In addition, measurements of geometrical features of wires for individual wire layers were made, evaluation of breakthroughs and properties of inner surface of shaped wires were carried out. During the tests, the technical condition of introducing ropes to endings in the form of cones after pulling the rope from the cup was also carried out.

The tests were carried out on selected sections of ropes:

- section with damaged wires in the form of cracks,

- rope section without damage at the entrance to the cone,

- reference section of the undamaged rope.

The selected section of the damaged rope for testing is shown in Figure 1. The test sections have been prepared with a length of approx. $900 \mathrm{~mm}$.

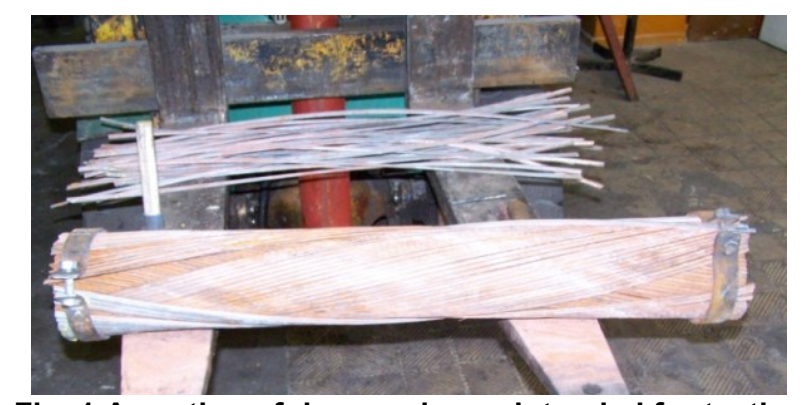

Fig. 1 A section of damaged rope intended for testing

Strength tests were carried out according to object standards. The drawing diagrams showing the methods of performing these tests are shown in Figure 2, where: 


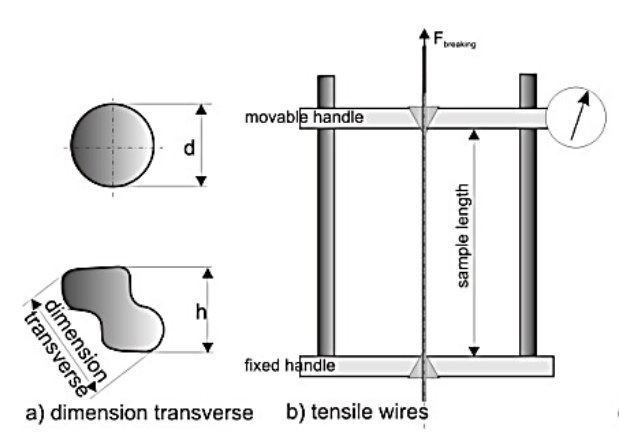

Fig. 2 Diagrams of carrying out strength tests

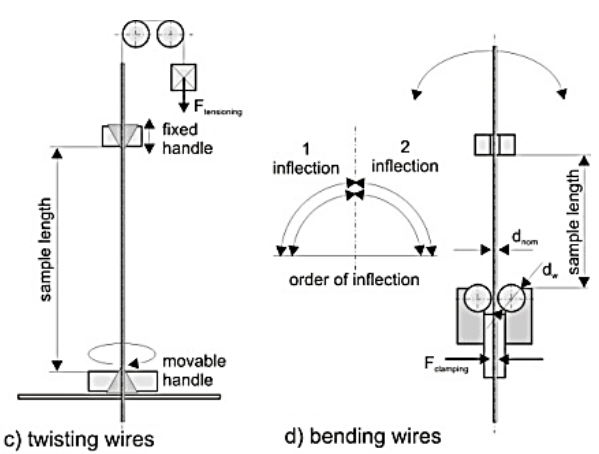

d) bending wires

Fig. 2a shows how to measure the geometrical dimension of wires. Such a measurement does not give the possibility of obtaining good accuracy, which is a problem when a standard size of a shaped wire, which is its height $h, \mathrm{~mm}$ is measured without a special device. Knowing the transverse dimension is needed to determine the mass consumption.

Fig. $2 \mathrm{~b}$ presents the static tensile test according to EN-ISO 6892-1: 2016-09 Metallic materials - Tensile testing - Part 1: Method of test at room temperature. Sample preparation involves the appropriate fixing of the wire in the holders of the testing machine. The test is carried out until the wire ruptures, and results in the value of the force at which the rupture occurred. The nature of the crosssection of the broken wire allows to determine if it was so-called rupture with the neck indicating a good fine-grained structure, or the wire has a different structure. The value of the breaking force and the knowledge of the crosssection of the wire allows to calculate the wire's tensile strength $\mathrm{Rm}, \mathrm{MPa}$.

Fig. 2c shows the bending test according to ISO 7801 - Metallic materials - Wire - Reverse bend test. This standard defines the resistance of wire with dimensions from 0.3 to $10.0 \mathrm{~mm}$ to plastic deformation during a bidirectional bending test. The test parameters were as follows: length of $500 \mathrm{~mm}$ diameter wire strands, clamping distance at $75 \mathrm{~mm}$ bending, $40 \mathrm{~mm}$ shaft diameter, 400 $\mathrm{mm}$ circular wire segments length, clamping distance at $75 \mathrm{~mm}$ bending, shaft diameter $30 \mathrm{~mm}$. During the test, the number of bends is recorded to break the wire.

Fig. $2 d$ presents the unidirectional twisting test according to the ISO $7800-$ Metallic materials - Wire - Simple torsion test. This standard defines the resistance of wire from 3.0 to $10.0 \mathrm{~mm}$ to plastic deformation during a one-way torsion test. The drawing shows the twister enabling the execution of this test. This is the most important test, based on the results, which determines what plastic properties a given wire has. (Olszyna, Tytko 2013). The sample preparation consists in the appropriate fixing of the sample in the machine and initial loading with a suitable force, which was approx. $600 \mathrm{~N}$ for shaped wires and approx. $660 \mathrm{~N}$ for round wires. The length of the samples was $410 \mathrm{~mm}$ for shaped wires and $470 \mathrm{~mm}$ for round ones. During the test, the number of revolutions until the wire breaks is recorded.

The first result of the research was the statement that the subject ropes differ significantly in the way of execution from the parameters specified in the 
documentation. The proper construction of guy ropes determined on the basis of real ropes is:

- cored wire

1 round wire $\varnothing 5,10 \mathrm{~mm}$

- 1 layer

6 round wires $\varnothing 5,10 \mathrm{~mm}$

- 2 layer

12 round wires $\varnothing 5,10 \mathrm{~mm}$

- 3 layer

18 round wires $\varnothing 5,10 \mathrm{~mm}$

- 4 layer

24 round wires $\varnothing 5,10 \mathrm{~mm}$

- 5 layer

31 shaped wires

- 6 layer

37 shaped wires

- 7 layer

45 shaped wires

- 8 layer

51 shaped wires

- 9 layer

58 shaped wires

- 10 layer

65 shaped wires

Based on geometrical dimensions, it was determined that layers 5, 6 and 7 were made of shaped wires approx. $5 \mathrm{~mm}$ high, layers 8 and 9 were made of shaped wires approx. $6 \mathrm{~mm}$ high and layer 10 was made of shaped wires approx. $7 \mathrm{~mm}$ high. The wires in the individual layers of rope are twisted in the opposite direction, which ensures that the structure is not twisted. On the basis of the data, a drawing of the cross section of the rope was made, which is shown in Figure 3.

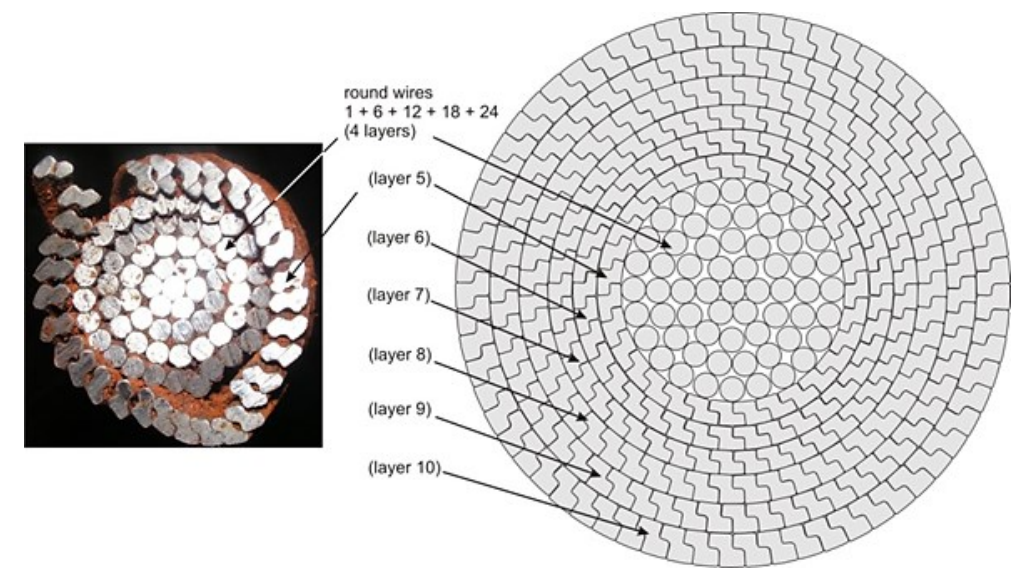

Fig. 3 Cross section of the enclosed structure test rope $115 \mathrm{~mm}$ in diameter

\section{RESEARCH RESULTS}

On the basis of the conducted tests, the results were obtained for the following geometrical and strength parameters of the ropes:

- measurement of geometric dimensions, mm

- breaking force, daN,

- number of bends,

- number of sprains.

The results were grouped for each layer separately:

- layers of round wires (designation: layer 4),

- layer of shaped wires No. 5 (denomination: layer 5),

- layer of shaped wires No. 6 (denomination: layer 6),

- layer of shaped wires No. 7 (denomination: layer 7), 
- layer of shaped wires 8 (designation: layer 8),

- layer of shaped wires No. 9 (denomination: layer 9),

- layer of shaped wires No. 10 (denomination: layer 10).

On the basis of these results, bar charts showing a given parameter for wires from one layer for all three tested sections of ropes were made (Olszyna, Tytko 2015). This presentation aims at a visual comparison of a given wire parameter in the same layer with other ropes. The main goal was to determine how the consumption changes depending on the position of the wire in the rope (layer) and the place of origin of the tested section of the rope. Selected results are presented in the Figures below on numbers from 4 to 5 for one of the layers according to their numbering, in series of four drawings: geometric dimension, breaking force, bending and twisting.
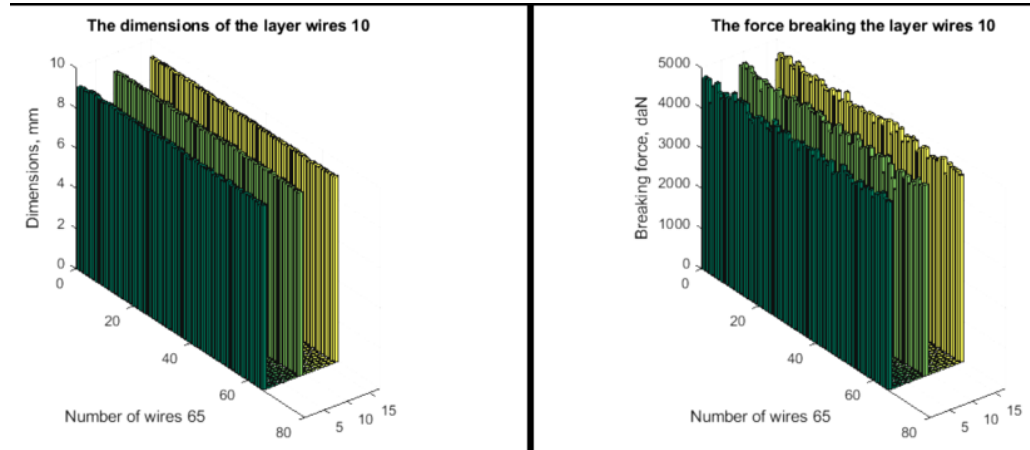

Fig. 4 Geometrical dimensions ( $\mathrm{mm}$ ) (left) and breaking force (daN) (right) of the wires of layers No. 10 (bars on the left: rope damaged, in the middle: rope undamaged, on the right: reference rope)
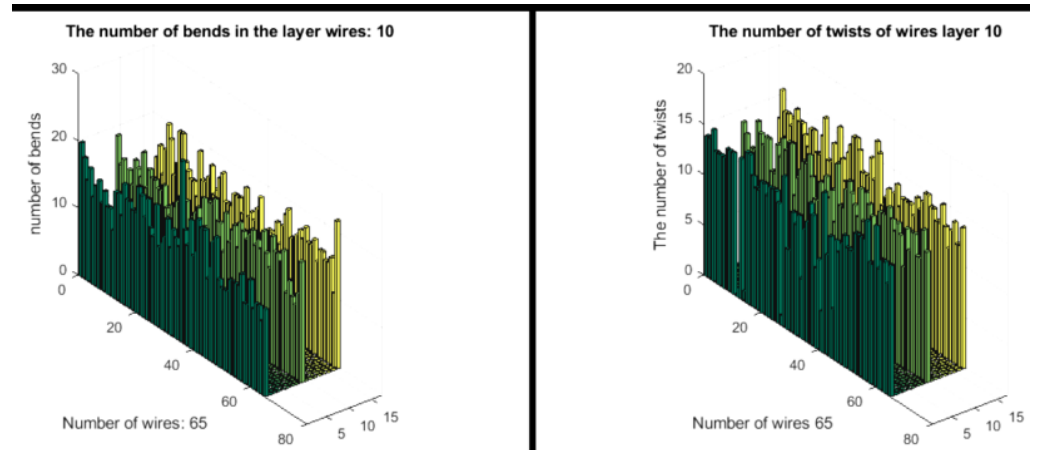

Fig. 5 Number of bends (on the left) and number of twists (daN) (on the right) of wires forming layers No. 10 (bars on the left: rope damaged, inside: rope undamaged, on the right: reference rope)

During the preparation of the test material during the unraveling phase, a corrosive coating was found, which in the form of brown powder spilled out of the ropes. This flight was evenly distributed over the surface of all wires in all ropes. Inside the ropes were dry, and all the wires were small inequalities. In general, they did not have the character of sharp notches, but rather gentle dents. Surfaces of several layers of rope wires reference is shown in Figures 6 and 7 . The layers of wires of all the ropes after intersection spontaneously opened, which can be seen in Fig. 3, on which the inner part of the rope with layers is shown on the left. 


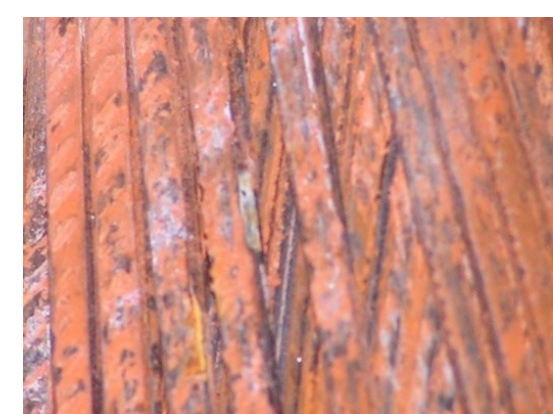

Fig. 6 The surface of the wires of layer 8 of the undamaged rope

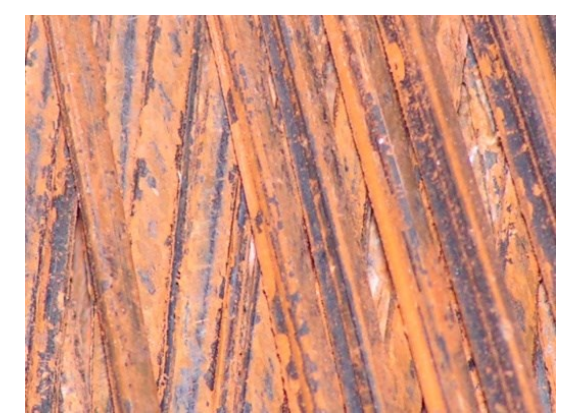

Fig. 7 Surface of wires of layer 9 of undamaged rope

During the endurance tests, the following observations of a more general nature were made:

- in the damaged rope most of the 10 layer wires cracked at the upper jaw of the machine (an unfavourable symptom related to wire defects),

- in the rope damaged in the remaining layers the wires cracked in the middle of the length of the segment or up to $100 \mathrm{~mm}$ from the lower jaw (normal symptom),

- in the rope of undamaged wires the fourth layer (round $\varnothing 5.10 \mathrm{~mm}$ ) cracked splitting in the lower jaws of the twister (wire drawing fault).

The conducted research allows to compare the change of a given parameter in individual layers of individual ropes. The conducted tests also allowed to determine the actual breaking force for given rope sections as shown in Figure 8.

The total strength of the rope breaking, $\mathrm{kN}$

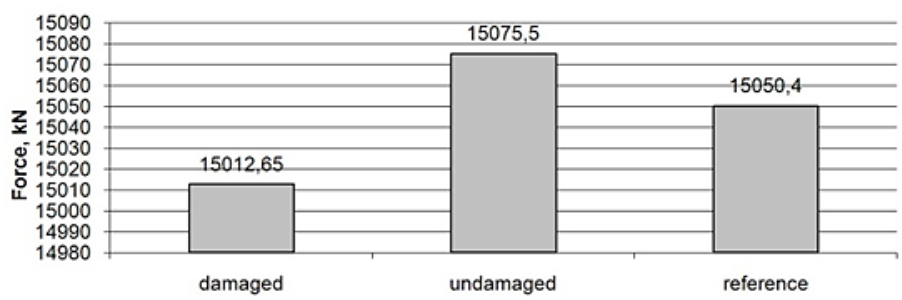

Fig. 8 Total forces breaking the individual test ropes

The presented research results indicate very small numerical differences in the values of measured parameters. Bar charts show that there is little variation in parameters in individual layers. Additional statistical analyzes were performed to obtain the confirmation. They consist in determining not only average parameters but statistical distributions of these parameters around the average 
value. The results are presented in Figures 9 to 12 (wire size distribution, wire breaking force distribution, distribution of number of bends and number of sprains that destroy wires) in layer 10.
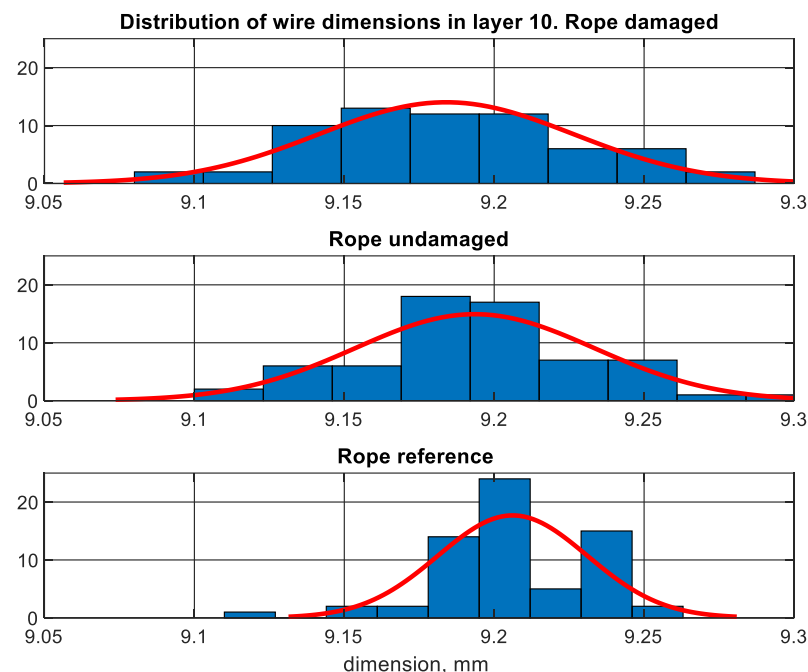

Fig. 9 The distribution of geometrical dimensions of wires in layers no. 10 of tested ropes
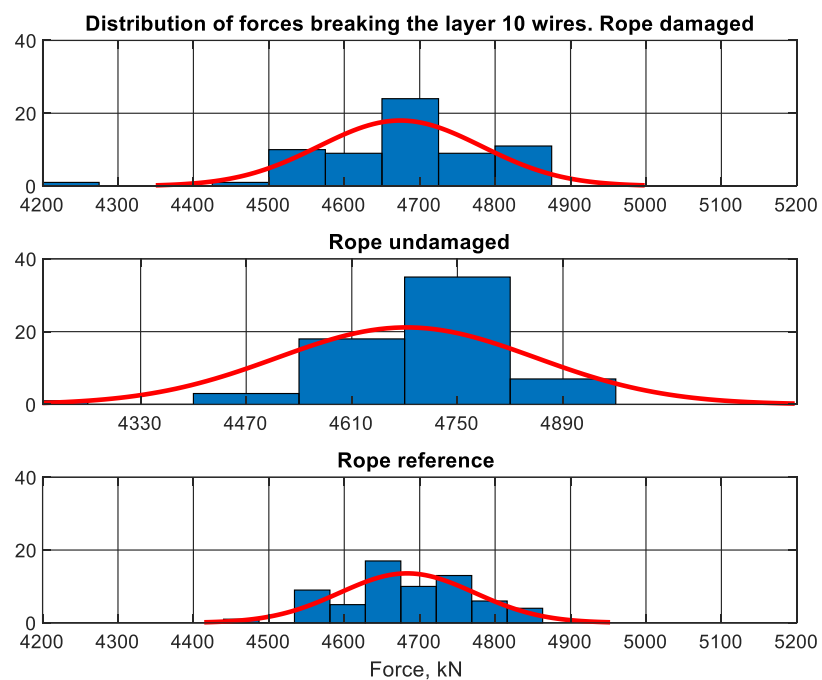

Rys. 10 Distribution of breaking forces in layers no. 10 of examined ropes
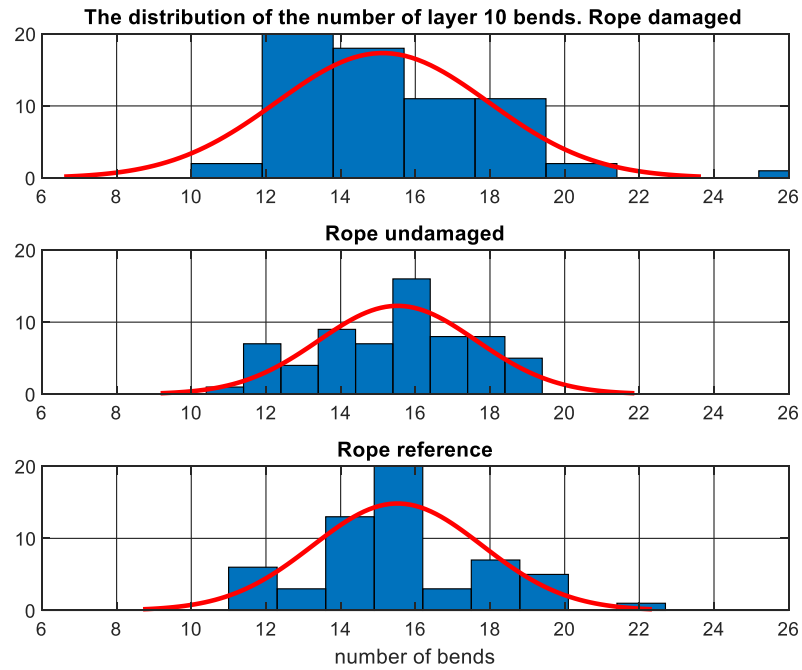

Rys. 11 Distribution of the number of wire bends in layers No. 10 of tested ropes 

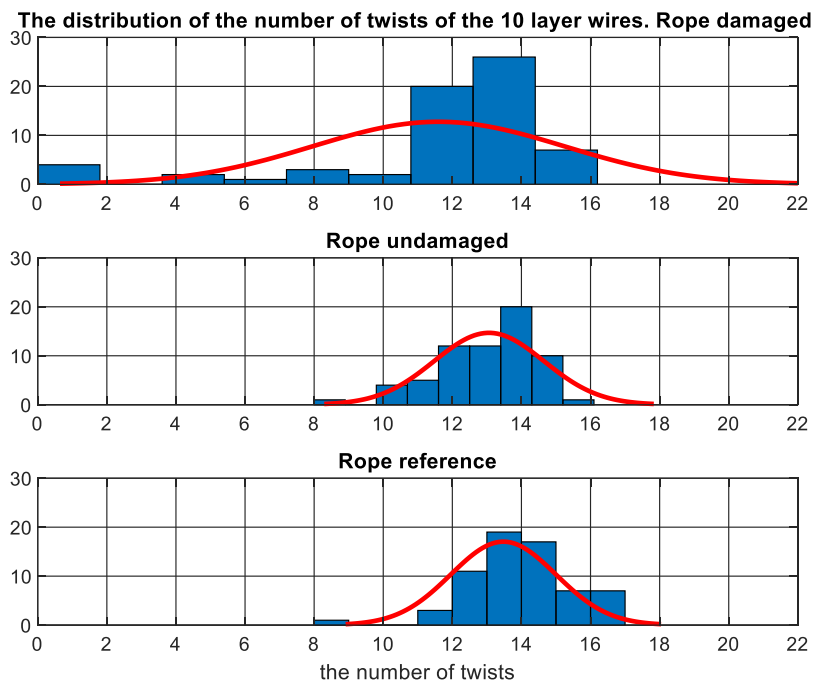

Rys. 12 Distribution of the number of sprains in layers no. 10 of tested ropes

Based on the research and analyzes carried out, hypotheses can be formulated. Mass losses in individual layers are diverse. They go down towards the inside of the rope and are the largest in the outer layers. They go down towards the inside of the rope and the largest are in the outer layers. These cannons in the damaged lines are the largest. he undamaged rope was better than the damaged one but much worse than the reference rope. In the wires of the outer layers of the damaged rope, there was a clear differentiation of the dimensions of the wires compared to the reference line. The actual safety coefficient of the ropes used in relation to the determined total strength forces breaking the rope in its entirety and with the adoption of a mechanical efficiency coefficient of 0.9 (average for the ropes of the closed structure) was exactly 3 . This is in accordance with the technical documentation and means that during the longterm operation of ropes, this coefficient has not changed. Despite the small variation in the values of total forces in the damaged line, there is a significant dispersion of the forces breaking the individual wires. Obtained results of strength tests in the form of number of bends and number of twists clearly indicate that the tested wires of the damaged rope have a reduced fatigue life. A rope that is not damaged in the context of fatigue life does not differ much from the reference rope.

\section{CONCLUSIONS}

The extraction lines are evenly corroded and corrosion has a surface character. The direct cause of cracks was material fatigue induced by cyclic variables. The tested section of the rope near the cone grip did not show a decrease in the fatigue life of the wires in the immediate vicinity of the grip. The experimentally determined actual value of the safety factor indicates that the criteria adopted for depositing the ropes of the closed structure are correct.

\section{REFERENCES}

Kasztelewicz Z. (2012) Koparki wielonaczyniowe i zwałowarki taśmowe. Technologia pracy. Wydawn. Agencja Wydawniczo-Poligraficzna ART-Tekst, Kraków. 
Olszyna G., Tytko A., Sioma A. (2013) Assessment of the condition of hoisting ropes by measuring their geometric parameters in a three-dimensional image of their surface. Archives of Mining Sciences, Archiwum Górnictwa vol. 58 no. 3 pp. s. 643-654.

Olszyna G., Tytko A.(2015). Zagadnienie zużycia lin stalowych pracujących w układach wielokrążkowych. W: Bezpieczeństwo pracy urządzeń transportowych w górnictwie. Monografia. CBiDGP Sp. z o.o., Lędziny pp. 95-107.

Tytko A (2003). Eksploatacja lin stalowych. Wydawnictwo Śląsk, Katowice.

Tytko A.(2011), Strenght testing of retired main hoist ropes of bucket wheel excavators. Safe Use of Ropes OIPEEC conference, Texas, 22 $\div 24$ March 2011, pp. 51-59

Tytko A. i in. (2013) Badania wytrzymałościowe zdemontowanych lin odciągowych. Praca badawcza niepublikowana wykonana dla KWB Bełchatów.

\begin{abstract}
.
Basic opencast mining machines belong to the group of devices used to perform specific technological operations through mining, loading, transport up to the dumping of mining heaps. Machines work in EBD systems (Excavator-Belt-Dumping) and require high reliability. Multi-bucket excavators that require the use of rope systems in order to maintain stability and the possibility of mining at different levels. The paper focuses on issues related to rope work in multi-buckets excavators. On the basis of studies to assess the technical condition of the ropes identifies the causes of damage to ropes these machines. As a result of the research, final conclusions were formulated.
\end{abstract}

Keywords: wire rope, opencast mining, rope damage 